\title{
RESEARCH ON ELECTRICITY SUPPLY CHAIN STRATEGY COORDINATION CONSIDERING PEAK-VALLEY PRICING POLICY AND SERVICE QUALITY INVESTMENT
}

\author{
Wei Chen ${ }^{1}$, HaOmin WAng ${ }^{2, *}$ (1) And Jingbin $\mathrm{HE}^{3}$
}

\begin{abstract}
An electricity supply chain game model composed of electricity generation enterprise and electricity retailer enterprise is constructed to evaluate the impact of service quality and peak-valley pricing on electricity supply chain coordination mechanism. Decisions on electricity service quality and peak-valley pricing are studied. Following this, the contract coordination under the electricity supply chain is discussed. Based on the game framework, the main research results are as follows. First, the centralized system provides a lower peak-valley price and higher electricity service quality, electricity demand, and supply chain's profit compared with the decentralized system. Second, with the service quality sensitivity coefficient, the electricity service quality, electricity price, and electricity demand increase, increasing the profit. Third, with the electricity service quality cost coefficient, the electricity service quality, electricity price, and electricity demand decrease, reducing the profit. Fourth, revenue sharing and an electricity service quality investment cost-sharing contract could achieve the coordination of the supply chain.
\end{abstract}

Mathematics Subject Classification. 91A 80.

Received September 4, 2021. Accepted February 5, 2022.

\section{INTRODUCTION}

Since the reform of the electricity system, the business model of China's electricity market has undergone great changes, from the original integrated sales model to the separate sales model [11]. In the integrated sales model, both electricity generation enterprises and electricity retailer enterprises would pursue system profit maximization. In the sale separation model, electricity generation enterprises have electricity generation equipment and related assets, which could carry out electricity production activities. Electricity retailer enterprises have transmission and distribution equipment and related assets, which could carry out electricity sales activities. These enterprises will seek to maximize their profits.

Keywords. Electricity service quality, electricity supply chain, peak-valley pricing.

1 College of Management Science, Chengdu University of Technology, Chengdu 610059, P.R. China.

2 School of Economic Information Engineering, Southwestern University of Finance and Economics, Chengdu 610074,

P.R. China.

3 School of Management and Economics, University of Electronic Science and Technology of China, Chengdu 611731, P.R. China

*Corresponding author: cn_whm@163.com

(c) The authors. Published by EDP Sciences, ROADEF, SMAI 2022 
The sale separation model greatly impacts the electricity supply chain's decision-making, especially on the electricity retailer enterprise. On the one hand, the electricity retailer enterprise formulates the peak-valley pricing policy to balance the electricity consumption between the peak and valley periods. Therefore, the electricity retailer enterprise formulates different electricity prices and transfers the electricity consumption in the peak period to the valley period $[12,17]$. For example, Hubei and Gansu have implemented the peakvalley pricing policy ${ }^{1}$. On the other hand, the electricity retailer enterprise improves market competitiveness by improving the electricity service quality. High-quality electricity would attract more consumers. For example, Guangdong's financial high-tech service zone has attracted more than 260 well-known enterprises to settle down because it provides high-quality electricity ${ }^{2}$.

The electricity peak-valley pricing policy and electricity service quality have been applied to the electricity market, affecting consumers' purchasing behaviors. Therefore, this study solves the following questions:

(1) What are the impacts of the electricity peak-valley pricing policy and electricity service quality on the electricity demand and profits?

(2) What kind of contracts could be designed to improve the profits of the electricity supply chain?

This paper constructs an electricity supply chain established by an electricity generation enterprise and an electricity retailer enterprise to make the peak-valley pricing and service quality decision and solve the above questions. The findings are based on the equilibrium results between the decentralized system and the centralized system. First, the effects of the electricity service quality sensitivity, electricity service quality cost coefficient, and electricity production cost on the equilibrium solution are analyzed. Second, the equilibrium peak-valley pricing, electricity demand, electricity service quality, and profit are compared. Finally, a combined contract of revenue sharing and electricity service quality cost-sharing is proposed to coordinate the supply chain.

This paper has the following contributions. First, it analyzes the research on peak-valley pricing and service quality decision-making under the decentralized and centralized systems and designs corresponding contracts to coordinate the electricity supply chain, further enriching the electricity market research. Second, it compares the advantages and disadvantages of centralized and decentralized systems. It was determined that the centralized system would provide a lower peak-valley price, higher electricity service quality, electricity demand, and supply chain profit. Moreover, the revenue sharing and electricity service quality investment cost-sharing contract could achieve the coordination of the supply chain. These conclusions are also helpful for the operation of the electricity market.

\section{Literature REVIEW}

This paper is related to two areas: peak-valley pricing policy and service quality. These areas constitute the focus of this paper, and the above parts are reviewed in detail.

\subsection{Peak-valley pricing policy}

The existing research on peak valley pricing mainly focuses on renewable energy investments and electricity demands. Concerning the investment literature, for example, Mills et al. [21] used 15 min intervals of 24 actual commercial photovoltaic devices to collect photovoltaic data of commercial users in California. They discussed the impact of the peak-valley pricing policy on photovoltaic electricity generation investments. They found that peak-valley pricing is conducive to photovoltaic electricity generation investment. Chao [4] considered the electricity generation cost and renewable energy investment with more general peak-valley pricing (dynamic pricing). They found that this pricing could reduce the electricity generation cost and promote the investment of renewable energy. Kök et al. [16] studied the impact of electricity price on renewable energy investment under a profit maximization model. They found that peak valley pricing is more conducive to renewable energy

\footnotetext{
$1_{\text {https: //www.ty2808.com/news/2781.html. }}$

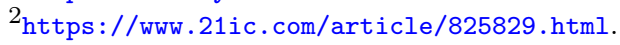


investment than under flat pricing. The above literature notes that peak valley pricing is conducive to renewable energy investment. Miao et al. [20] built a model of wind storage with the peak-valley pricing policy. They found it could convert the cheap electricity price in the valley period into the peak period and reduce the loss from the deviation of supply and demand. Han et al. [14] discussed the renewable energy between the distribution and $5 \mathrm{G}$ mobile networks under the peak-valley price policy and found that the collaborative optimization theory could increase the efficiency of renewable energy. Yao et al. [27] discussed renewable energy in 2030 as the transformation electricity systems under the peak-valley price policy and found that the photovoltaic electricity would decrease while the wind electricity would increase before 2030 with the electric vehicles increasing.

The above literature focuses on renewable energy investment, but this paper differs from the above literature. First, the above literature mainly adopts the optimization method. However, this paper constructs the game theory framework and describes the electricity supply chain composed of electricity generation enterprise and electricity retailer enterprise. Second, the above literature does not consider the electricity service quality, one of the factors affecting consumer purchasing of electricity. This paper brings the electricity service quality into the framework of the game theory, further enriching the electricity market research.

Further, concerning electricity demand, for example, Darghouth et al. [9] explored the impact of peak-valley pricing on photovoltaic demands. The research found that the peak electricity price is conducive to increasing the photovoltaic demand. Faruqui and Sergici [13] studied the impact of peak valley pricing on consumers' electricity consumption behavior. They found that consumers are responsive to the peak valley pricing policy and transfer the electricity consumption in the peak period to that in the valley period. Borenstein [2] considered more general peak-valley pricing (dynamic pricing) to study the impact of peak-valley pricing on consumers' electricity consumption. They found that the peak-valley pricing policy will reduce the electricity cost of low-consumption consumers but increase the electricity cost of high-consumption consumers. Chen et al. [6] discussed the peakvalley price policy with the low-carbon technology investment and found that the benchmarking mechanism is better than the grandfathering mechanism in low-carbon technology investments and electricity demands.

The above literature considers the impact of the peak valley pricing policy on electricity demand. However, this paper differs from the above literature. First, the above literature noted that the peak valley pricing policy would increase the electricity demand. However, based on the peak valley pricing policy, this paper considers the problem of contract design and notes that the electricity demand under the centralized system is higher than that under the decentralized system. Second, this paper considers the peak-valley pricing decision between the centralized system and decentralized system, respectively, and brings the electricity market into the contract field.

\subsection{Service quality}

In recent years, research on product quality in supply chain management has become a hot topic, mainly reflected in the product quality improvement of upstream manufacturers and the service quality improvement of downstream retailers.

For example, Dan et al. [8] studied the extended warranty service strategy of the dual-channel supply chain with value-added service competition concerning the improvement of upstream product quality. Manufacturers and retailers sell homogeneous durable goods with extended warranty services produced by the manufacturer and provide free value-added services. It is found that when the manufacturer improves the extended warranty service level, the competition for the value-added services weakened. There will be no value-added service competition when the quality assurance service level is high enough. Chen et al. [5] studied price and product quality improvement decision-making in the dual-channel supply chain. They found that the addition of a new channel can improve product quality and supply chain performance. The above literature mainly focuses on product quality improvement at the upstream manufacturer, while this paper focuses on service quality improvement at the downstream retailer. Sarkar et al. [23] discussed the production system with quality investment in the supply chain. They found that flexible production could reduce defective production and improve quality. Sarkar et al. [24] discussed the production system in a sustainable supply chain with carbon emissions and production quality. They found that the optimal solution could be obtained, and the carbon emissions could be reduced. 
Pal et al. [22] discussed the imperfect production inventory model with production quality under different credit mechanisms. They found that manufacturers should provide more credit to increase profits, and the quality may harm the supply chain.

The above literature focuses on product quality. However, there are significant differences between this paper and the above literature. First, the decision-makers are different. The above literature concerns the investment product quality of upstream enterprises, whereas this paper concerns the investment service quality of downstream enterprises. Second, this paper studies the peak-valley pricing strategy in the electricity market and describes it through the demand function. Thus, the characteristics of the electricity market are characterized through peak-valley pricing to affect consumers' purchase behavior.

Further, there have been studies on service quality. For example, Tsay and Agrawal [25] studied the problem that manufacturers provide common products to two independent retailers, and the retailers compete for service quality and price. They found that retailers will improve service quality and price competition intensity. Liu et al. [19] constructed a supply chain composed of a logistics service provider and logistic service integrator and considered the service quality defect commitment. They found that the quality defect commitment of logistics service providers decreased with the increase of customer demand elasticity for quality defect assurance. Yang and Xiao [26] discussed the coordination mechanisms in a supply chain with loss-averse consumers. They found that the quantity discount contract with the service subsidy could coordinate the supply chain. Ertekin [10] discussed the impact of the retailer's service quality on returns. They found that the return probability is low in stores with high friendliness, competitiveness, and pleasant environments. Although the above literature considers the service quality of retailers, they do not consider peak-valley pricing, a unique phenomenon in the electricity market. Alzaydi et al. [1] discussed the intangible service quality with retailers under COVID-19. They found that intangible service quality could promote perceived trust. Cao and Min [3] discussed the service quality in a dual-channel supply chain and found that increasing the service quality may harm the retailer since the wholesale price increases. Both this paper and the above literature consider the investment service quality of downstream enterprises. However, there are differences. First, this paper takes the electricity market as the research background and describes the characteristics of peak valley pricing. Different pricing strategies would affect the decision-making of the supply chain system. Second, this paper analyzes the electricity supply chain from the perspective of the contract, and the revenue sharing and an electricity service quality investment cost-sharing contract could achieve the coordination of the supply chain.

\section{MODEL FRAMEWORK}

There is an electricity generation enterprise and an electricity retailer enterprise in a certain area. The peak-valley pricing policy and electricity service quality are considered. Specifically, the electricity generation enterprise produces electricity, and the electricity retailer enterprise provides the electricity quality service and is set with peak-valley pricing. This paper makes the following assumptions.

Assumption 3.1. The electricity generation enterprise produces undifferentiated electricity with the unit production cost of $c$. It further sets the peak-valley wholesale electricity price $\left(w_{d}, w_{n}\right)$, where $w_{d}$ represents the peak wholesale electricity price and $w_{n}$ represents the valley wholesale electricity price.

Assumption 3.2. The electricity retailer enterprise purchases electricity from the electricity generation enterprise. First, the electricity retailer enterprise invests in the electricity service quality, and the investment cost function is as follows:

$$
G(k)=\frac{1}{2} h k^{2}
$$

where $h$ is the investment cost coefficient of the electricity service quality. A higher $h$ means a lower investment efficiency. $k$ is the electricity service quality. A higher $k$ means more electricity service quality investments. Such investment cost functions are widely used, such as Li and Li [18] and Zhou et al. [28]. 
Second, the electricity retailer enterprise formulates the peak valley electricity price $\left(p_{d}, p_{n}\right)$ to balance the electricity consumption in different periods to transfer the peak electricity consumption period to the valley period. $p_{d}$ represents the peak electricity price and $p_{d}$ represents the valley price.

Assumption 3.3. Consumers' electricity consumption depends on the peak and valley electricity prices and the electricity service quality. Based on the research of Kök et al. [16] and Dan et al. [8], it is assumed that the electricity demand functions in the peak and valley periods are, respectively, as follows:

$$
\left\{\begin{array}{c}
q_{d}=a_{d}-p_{d}+b p_{n}+d k \\
q_{n}=a_{n}-p_{n}+b p_{d}+d k
\end{array}\right.
$$

where $a_{d}$ represents the potential market demand scale in the peak period and $a_{n}$ represents the potential market demand scale in the valley period. In fact, the potential market scale in the peak period is greater than that in the valley period $a_{d}>a_{n}$. Further, $b$ represents the degree of price competition between the peak and valley periods and $d$ is the sensitivity of consumers to the electricity service quality.

Assumption 3.4. It is assumed that both the electricity generation enterprise and the electricity retailer enterprise aim to maximize their respective profits. Then, the profit functions of the electricity generation enterprise and electricity retailer enterprise are, respectively, as follows:

$$
\begin{aligned}
\pi_{r}^{e} & =\left(p_{d}-w_{d}\right) q_{d}+\left(p_{n}-w_{n}\right) q_{n}-\frac{1}{2} h k^{2} \\
\pi_{m}^{e} & =w_{d} q_{d}+w_{n} q_{n}-c\left(q_{d}+q_{n}\right) .
\end{aligned}
$$

Based on equations (3.3) and (3.4), an electricity supply chain model is constructed, with the electricity generation enterprise as the leader and the electricity retailer enterprise as the follower. The operation decisionmaking sequence of the electricity supply chain is as follows. First, the electricity generation enterprise decides the peak valley wholesale price $\left(w_{d}, w_{n}\right)$. Second, the electricity retailer enterprise makes decisions on the electricity service quality and peak valley electricity price $\left(k, p_{d}, p_{n}\right)$. Finally, the parameters should meet the following conditions: $a_{d}+a_{n}>2 c(1-b) h>\frac{2 d^{2}}{(1-b)}$ to ensure that the equilibrium results are greater than zero.

This paper will consider three kinds of game models: the decentralized system, the centralized system, and the coordinated system. The above superscripts $e^{*}, c^{*}$, and $s^{*}$ represent the equilibrium results of the above models to distinguish them.

\section{DeCEntralized SyStem}

In the decentralized system, both the electricity generation and electricity retailer enterprises take their profit maximization as the decision-making goal and choose the optimal equilibrium operation decision. First, the peak-valley wholesale electricity price $\left(w_{d}, w_{n}\right)$ is decided by the electricity generator enterprise. Following this, the electricity retailer enterprise would make decisions on the electricity service quality and peak-valley electricity price $\left(k, p_{d}, p_{n}\right)$ to maximize profits $\left(\pi_{m}^{e}, \pi_{r}^{e}\right)$ as their respective objectives.

Using a reverse induction, we obtain the equilibrium electricity service quality and peak valley electricity price $\left(k^{e^{*}}, p_{d}^{e^{*}}, p_{n}^{e^{*}}\right)$ from equation (3.3) as follows:

$$
\begin{aligned}
k^{e^{*}}= & \frac{d\left[a_{d}+a_{n}-(1-b)\left(w_{d}+w_{n}\right)\right]}{2\left[(1-b) h-d^{2}\right]} \\
p_{d}^{e^{*}}= & \frac{\left\{\begin{array}{c}
a_{d}\left(2 h-d^{2}\right)+a_{n}\left(d^{2}+2 b h\right) \\
-(1+b)\left\{w_{d}\left[3 d^{2}-2 h(1-b)\right]+w_{n} d^{2}\right\}
\end{array}\right\}}{4(1+b)\left[(1-b) h-d^{2}\right]}
\end{aligned}
$$




$$
p_{n}^{e^{*}}=\frac{\left\{\begin{array}{c}
\left(d^{2}+2 b h\right) a_{d}+\left(2 h-d^{2}\right) a_{n} \\
-(1+b)\left\{d^{2} w_{d}+w_{n}\left[3 d^{2}-2 h(1-b)\right]\right\}
\end{array}\right\}}{4(1+b)\left[(1-b) h-d^{2}\right]} .
$$

Substituting equations (4.1)-(4.3) for equation (3.4), the electricity generation enterprise would decide the optimal peak-valley wholesale price $\left(w_{d}, w_{n}\right)$. We can determine the equilibrium peak-valley wholesale price $\left(w_{d}^{e^{*}}, w_{n}^{e^{*}}\right)$ as follows:

$$
\begin{aligned}
& w_{d}^{e^{*}}=\frac{a_{d}+b a_{n}+c-b^{2} c}{2-2 b^{2}} \\
& w_{n}^{e^{*}}=\frac{c+b a_{d}+a_{n}-b^{2} c}{2-2 b^{2}} .
\end{aligned}
$$

Further, by substituting equations (4.4), (4.5) for equations (4.1)-(4.3), the equilibrium electricity service quality and peak valley electricity price $\left(k^{e^{*}}, p_{d}^{e^{*}}, p_{n}^{e^{*}}\right)$ can be obtained as follows:

$$
\begin{aligned}
k^{e^{*}}= & \frac{d\left[a_{d}+a_{n}-2 c(1-b)\right]}{4\left[(1-b) h-d^{2}\right]} \\
p_{d}^{e^{*}}= & \left\{\begin{array}{c}
a_{d}\left[6 h(1-b)-(5-b) d^{2}\right] \\
+a_{n}\left[(1-5 b) d^{2}+6 b h(1-b)\right] \\
+2 c\left(1-b^{2}\right)\left[(1-b) h-2 d^{2}\right]
\end{array}\right\} \\
8\left(1-b^{2}\right)\left[(1-b) h-d^{2}\right] & \left\{\begin{array}{c}
a_{d}\left[(1-5 b) d^{2}+6 b h(1-b)\right] \\
+a_{n}\left[6 h(1-b)-(5-b) d^{2}\right] \\
+2 c\left(1-b^{2}\right)\left[(1-b) h-2 d^{2}\right]
\end{array}\right\} \\
p_{n}^{e^{*}}= & \frac{8\left(1-b^{2}\right)\left[h(1-b)-d^{2}\right]}{}
\end{aligned}
$$

Substituting equations (4.4)-(4.8) for equations (3.2)-(3.4) can determine the optimal peak valley electricity demand $\left(q_{m}^{e^{*}}, q_{r}^{e^{*}}\right)$ and supply chain enterprise's profit $\left(\pi_{m}^{e^{*}}, \pi_{r}^{e^{*}}\right)$ as follows:

$$
\begin{aligned}
& q_{d}^{e^{*}}=\frac{2 \operatorname{ch}(1-b)^{2}+a_{d}\left[2 h(1-b)-d^{2}\right]+a_{n} d^{2}}{8\left[(1-b) h-d^{2}\right]} \\
& q_{n}^{e^{*}}=\frac{2 \operatorname{ch}(1-b)^{2}+a_{d} d^{2}+a_{n}\left[2 h(1-b)-d^{2}\right]}{8\left[h(1-b)-d^{2}\right]} \\
& \pi_{r}^{e^{*}}=\frac{\left\{\begin{array}{c}
4(1-b)^{2}(1+b) c^{2} h+\left(2 h-d^{2}\right)\left(a_{d}^{2}+a_{n}^{2}\right) \\
-4 c h a_{n}\left(1-b^{2}\right) \\
+2 a_{d}\left[\left(d^{2}+2 b h\right) a_{n}-2 c h\left(1-b^{2}\right)\right]
\end{array}\right\}}{32(1+b)\left[h(1-b)-d^{2}\right]}
\end{aligned}
$$

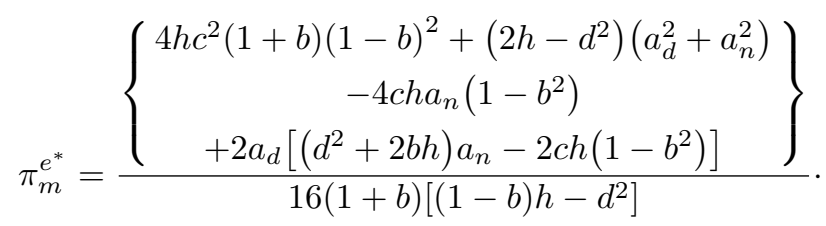


Proposition 4.1. In the decentralized system, the optimal peak-valley wholesale price $\left(w_{d}^{e^{*}}, w_{n}^{e^{*}}\right)$, electricity service quality $k^{e^{*}}$, peak-valley electricity price $\left(p_{d}^{e^{*}}, p_{n}^{e^{*}}\right)$ peak valley electricity demand $\left(q_{m}^{e^{*}}, q_{r}^{e^{*}}\right)$, and electricity supply chain enterprise profit $\left(\pi_{m}^{e^{*}}, \pi_{r}^{e^{*}}\right)$ can be given by equations (4.3)-(4.12), respectively.

Proposition 4.2. (1) Comparing the equilibrium peak electricity demand and valley electricity demand, there is $q_{n}^{e^{*}}<q_{d}^{e^{*}}$.

(2) Comparing the profits of supply chain enterprises, there is $\pi_{r}^{e^{*}}<\pi_{m}^{e^{*}}$.

Proposition 4.2 compares the optimal peak valley electricity supply and demand chain enterprise profits. The peak potential electricity market demand is higher than that in the valley period. Therefore, the peak electricity demand is greater than in the valley period. The electricity generation enterprise as a leader has the "first-mover advantage" and would give priority to making decisions in line with their profits. Meanwhile, the electricity retailer enterprise makes decisions later. Therefore, the profits of the electricity generation enterprise are greater than the profits of the electricity retailer enterprise. This explains the reason why supply chain enterprises compete for the "voice."

Proposition 4.3. With the increasing sensitivity coefficient of electricity service quality, we have (1) $\frac{\partial k^{e^{*}}}{\partial d}>0$; (2) $\frac{\partial p_{d}^{e^{*}}}{\partial d}>0, \frac{\partial p_{n}^{e^{*}}}{\partial d}>0 ;(3) \frac{\partial q_{d}^{e^{*}}}{\partial d}>0, \frac{\partial q_{n}^{e^{*}}}{\partial d}>0$.

Proposition 4.3 shows that with the increasing sensitivity coefficient of the electricity service quality, the optimal electricity service quality, peak-valley price, and peak valley electricity demand would increase. Consumers pay more attention to the level of the electricity service quality due to the increasing sensitivity coefficient of the electricity service quality. This would improve the enthusiasm of the electricity generator enterprise to invest in electricity service quality and promote its improvement. Moreover, the sensitivity of electricity service quality would promote the increase of consumers' electricity consumption. On the one hand, the electricity service quality sensitivity coefficient would encourage the electricity retailer enterprise to invest in electricity service quality. On the other hand, it would encourage consumers to use more electricity. The electricity retailer enterprise would adopt the strategy of increasing the electricity price to pursue higher profits. Therefore, improving consumers' sensitivity to electricity quality would encourage the electricity retailer enterprise to improve the electricity service quality and improve consumers' electricity consumption.

Proposition 4.4. With the cost coefficient of electricity service quality, we have (1) $\frac{\partial e^{e^{*}}}{\partial h}<0$; (2) $\frac{\partial p_{d}^{e^{*}}}{\partial h}<0$, $\frac{\partial p_{n}^{e^{*}}}{\partial h}<0 ;(3) \frac{\partial q_{d}^{e^{*}}}{\partial h}<0, \frac{\partial q_{n}^{e^{*}}}{\partial h}<0$.

Proposition 4.4 shows that with the cost coefficient of electricity service quality, the optimal electricity service quality, peak-valley electricity price, and peak-valley electricity demand all decrease. The increase of the cost coefficient of electricity service quality would reduce the efficiency of investing in electricity service quality, leading to an increase in the cost of electricity service quality. Therefore, the electricity retailer enterprise would reduce electricity service quality. The reduction of electricity service quality would reduce consumers' consumption under this service quality level. The electricity retailer enterprise would adopt the strategy of reducing the electricity price to slow the electricity demand reduction. Therefore, reducing the cost coefficient of electricity service quality is conducive to the investment in electricity service quality and improving the electricity demand.

Proposition 4.5. With the electricity production cost, we have (1) $\frac{\partial k^{e^{*}}}{\partial c}<0$; (2) $\frac{\partial p_{d}^{e^{*}}}{\partial c}>0$, $\frac{\partial p_{n}^{e^{*}}}{\partial c}>0$; (3) $\frac{\partial q_{d}^{e^{*}}}{\partial c}<0, \frac{\partial q_{n}^{e^{*}}}{\partial c}<0$.

Proposition 4.5 shows that with the electricity production cost, the optimal electricity service quality, peakvalley price, and peak-valley electricity demand all increase. The production efficiency of electricity generation 
enterprises would decrease due to the electricity production cost, resulting in the increase of the electricity production cost. This would lead to an electricity retailer enterprise increasing the electricity price and reducing the electricity service quality and demand. Therefore, reducing the production cost is conducive to increasing electricity service quality and improving consumers' electricity demand.

\section{Centralized system}

In the centralized system, the electricity generation enterprise and electricity retailer enterprise would take the profit maximization of the supply chain system. The electricity retailer enterprise does not need to pay the peak-valley wholesale price to the electricity generation enterprise. Therefore, the profit function of the electricity supply chain system is as follows:

$$
\pi^{c}=p_{d} q_{d}+p_{n} q_{n}-\frac{1}{2} h k^{2}-c\left(q_{d}+q_{n}\right) .
$$

Under the centralized system, the supply chain enterprise would make the service quality and peak valley electricity price decision $\left(k, p_{d}, p_{n}\right)$. The optimal service quality and peak valley electricity prices $\left(k^{c^{*}}, p_{d}^{c^{*}}, p_{n}^{c^{*}}\right)$ are as follows:

$$
\begin{aligned}
k^{c^{*}}= & \frac{d\left[a_{d}+a_{n}-2 c(1-b)\right]}{2\left[h(1-b)-d^{2}\right]} \\
p_{d}^{c^{*}}= & \frac{\left\{\begin{array}{c}
2 c(1+b)\left[(1-b) h-2 d^{2}\right] \\
+a_{d}\left(2 h-d^{2}\right)+a_{n}\left(d^{2}+2 b h\right)
\end{array}\right\}}{4(1+b)\left[h(1-b)-d^{2}\right]} \\
p_{n}^{c^{*}}= & \frac{\left\{\begin{array}{c}
2 c(1+b)\left[(1-b) h-2 d^{2}\right] \\
+a_{d}\left(d^{2}+2 b h\right)+a_{n}\left(2 h-d^{2}\right)
\end{array}\right\} .}{4(1+b)\left[(1-b) h-d^{2}\right]} .
\end{aligned}
$$

When substituting equations (5.2)-(5.4) for equations (3.1) and (4.12), the optimal peak-valley electricity demand $\left(q_{d}^{c^{*}}, q_{n}^{c^{*}}\right)$ and the optimal profit of the supply chain system $\left(\pi^{c^{*}}\right)$ are as follows:

$$
\begin{aligned}
q_{d}^{c^{*}}= & \frac{2 c h(1-b)^{2}+a_{d}\left[2(1-b) h-d^{2}\right]+a_{n} d^{2}}{4\left[(1-b) h-d^{2}\right]} \\
q_{n}^{c^{*}}= & \frac{a_{d} d^{2}+a_{n}\left[2(1-b) h-d^{2}\right]-2 c h(1-b)^{2}}{4\left[(1-b) h-d^{2}\right]} \\
\pi^{c^{*}}= & \frac{\left\{\begin{array}{c}
4 h c^{2}(1-b)^{2}(1+b)+\left(2 h-d^{2}\right) a_{d}^{2} \\
-4 c h a_{n}\left(1-b^{2}\right)+\left(2 h-d^{2}\right) a_{n}^{2} \\
+2 a_{d}\left[\left(d^{2}+2 b h\right) a_{n}-2 c h\left(1-b^{2}\right)\right]
\end{array}\right\}}{8(1+b)\left[(1-b) h-d^{2}\right]} .
\end{aligned}
$$

Proposition 5.1. In the centralized system, the optimal electricity service quality $k^{e^{*}}$ and electricity price $\left(p_{d}^{e^{*}}, p_{n}^{e^{*}}\right)$, electricity demand $\left(q_{m}^{e^{*}}, q_{r}^{e^{*}}\right)$, and electricity supply chain enterprise profit $\left(\pi_{m}^{e^{*}}, \pi_{r}^{e^{*}}\right)$ can be given by equations (5.2)-(5.7).

Proposition 5.2. Comparing the optimal solution of the centralized and decentralized system, we have (1) $k^{c^{*}}>k^{e^{*}} ;(2) p_{d}^{c^{*}}<p_{d}^{e^{*}}, p_{n}^{c^{*}}<p_{n}^{e^{*}} ;(3) q_{d}^{c^{*}}>q_{d}^{e^{*}}, q_{n}^{c^{*}}>q_{n}^{e^{*}} ;(4) \pi^{c^{*}}>\pi_{r}^{e^{*}}+\pi_{m}^{e^{*}}$. 
Proposition 5.2 shows that the supply chain enterprise would provide higher electricity service quality in the centralized system and set a lower electricity price to obtain a higher electricity demand and supply chain enterprise profits. In the centralized system, supply chain enterprises avoid internal transactions (expressed as the wholesale electricity price) and invest more in the electricity service quality to provide higher quality electricity service, reducing the cost of the electricity generator enterprise and the peak-valley electricity price. Therefore, the electricity demand and the profits of supply chain enterprises would increase. In the decentralized system, the electricity generation and electricity retailer enterprises pursue profit maximization. The existence of an internal transaction cost increases the electricity purchase cost of the electricity retailer enterprise, reducing the electricity service quality investment and increasing the peak-valley electricity price. It is necessary to design a coordination contract to improve the profit of the supply chain in the decentralized system. The contract coordination decision is analyzed.

\section{Coordinating System}

The result of Proposition 5.2 shows that compared with the centralized system, the equilibrium operation decision of the decentralized system is not optimal. Therefore, it is necessary to design contracts to coordinate the electricity supply chain. We set up a portfolio contract composed of electricity service quality investment cost-sharing and revenue sharing $(\gamma, \theta)$, which was implemented into the electricity supply chain. On the one hand, the electricity generation enterprise accepts the electricity service quality investment cost-sharing contract and bears $\frac{1}{2}(1-\gamma) h k^{2}$ to improve the electricity service quality of the electricity retailer enterprise. On the other hand, the electricity retailer enterprise provides profits for the electricity generation enterprises that obtained $(1-\theta)\left[\left(p_{d}-w_{d}\right) q_{d}+\left(p_{n}-w_{n}\right) q_{n}\right]$ to reduce the peak-valley wholesale price from the electricity generation enterprise. Therefore, the profit functions of the electricity retailer enterprise and electricity generation enterprise in the coordinated system are as follows:

$$
\begin{aligned}
& \pi_{r}^{s^{*}}=\theta\left[\left(p_{d}-w_{d}\right) q_{d}+\left(p_{n}-w_{n}\right) q_{n}\right]-\frac{1}{2} \gamma h k^{2} \\
& \pi_{m}^{s^{*}}=\left\{\begin{array}{c}
w_{d} q_{d}+w_{n} q_{n}-c\left(q_{d}+q_{n}\right) \\
-1 / 2(1-\gamma) h k^{2} \\
+(1-\theta)\left[\left(p_{d}-w_{d}\right) q_{d}+\left(p_{n}-w_{n}\right) q_{n}\right]
\end{array}\right\} .
\end{aligned}
$$

First, the electricity retailer enterprise decides on the optimal electricity price to maximize profits. We have an optimal peak-valley electricity price $\left(p_{d}^{s^{*}}, p_{n}^{s^{*}}\right)$ as follows:

$$
\begin{gathered}
p_{d}^{s^{*}}=\frac{\left\{\begin{array}{c}
2 c(1+b)\left[(1-b) h-2 d^{2}\right] \\
+a_{d}\left(2 h-d^{2}\right)+a_{n}\left(d^{2}+2 b h\right)
\end{array}\right\}}{4(1+b)\left[(1-b) h-d^{2}\right]} \\
p_{n}^{s^{*}}=\frac{\left\{\begin{array}{c}
2 c(1+b)\left[(1-b) h-2 d^{2}\right] \\
+a_{d}\left(d^{2}+2 b h\right)+a_{n}\left(2 h-d^{2}\right)
\end{array}\right\} .}{4(1+b)\left[(1-b) h-d^{2}\right]} .
\end{gathered}
$$

Further, when substituting equations (6.3) and (6.4) for equation (6.2), the optimal electricity service quality $\left(k^{e^{*}}\right)$ can be obtained as follows:

$$
k^{s^{*}}=\frac{d\left[a_{d}+a_{n}-2 c(1-b)\right]}{2\left[(1-b) h-d^{2}\right]} .
$$

Let $k^{s^{*}}=k^{c^{*}}, p_{m}^{s^{*}}=p_{m}^{c^{*}}$ and $p_{r}^{s^{*}}=p_{r}^{c^{*}}$, we have

$$
w_{d}^{s^{*}}=c
$$




$$
\begin{aligned}
w_{n}^{s^{*}} & =c \\
\gamma^{s^{*}} & =\theta^{s^{*}} .
\end{aligned}
$$

When substituting equations (6.6)-(6.8) for equations (6.1) and (6.2), the optimal supply chain enterprise's profit $\left(\pi_{r}^{s^{*}}, \pi_{m}^{s^{*}}\right)$ and the total supply chain profit $\left(\pi^{\mathrm{sc}^{*}}\right)$ can be obtained as follows:

$$
\begin{gathered}
\pi_{r}^{s^{*}}=\frac{\left\{\begin{array}{c}
4 h c^{2}(1+b)(1-b)^{2}+\left(d^{2}-2 h\right) a_{n}^{2} \\
+a_{d}\left[\left(2 h-d^{2}\right) a_{d}-4 c h\left(1-b^{2}\right)\right] \\
+2 a_{n}\left[\left(d^{2}+2 b h\right) a_{d}-2 c h\left(1-b^{2}\right)\right]
\end{array}\right\}}{8(1+b)\left[(1-b) h-d^{2}\right]} \\
\pi_{m}^{s^{*}}=\frac{(1-\theta)\left\{\begin{array}{c}
4 h c^{2}(1+b)(1-b)^{2}+\left(d^{2}-2 h\right) a_{n}^{2} \\
+a_{d}\left[\left(2 h-d^{2}\right) a_{d}-4 c h\left(1-b^{2}\right)\right] \\
+2 a_{n}\left[\left(d^{2}+2 b h\right) a_{d}-2 c h\left(1-b^{2}\right)\right]
\end{array}\right\}}{8(1+b)\left[(1-b) h-d^{2}\right]} \\
\pi^{\mathrm{sc}^{*}}=\pi^{c^{*}}=\frac{\left\{\begin{array}{c}
4 h c^{2}(1-b)^{2}(1+b)+\left(2 h-d^{2}\right) a_{d}^{2} \\
-4 c h a_{n}\left(1-b^{2}\right)+\left(2 h-d^{2}\right) a_{n}^{2} \\
+2 a_{d}\left[\left(d^{2}+2 b h\right) a_{n}-2 c h\left(1-b^{2}\right)\right]
\end{array}\right\}}{8(1+b)\left[(1-b) h-d^{2}\right]} .
\end{gathered}
$$

Proposition 6.1. (1) When adjusting the proportion of the income sharing $\theta$, the electricity generation enterprise and electricity enterprise can distribute the profits of the supply chain;

(2) When $\frac{1}{4} \leq \theta \leq \frac{1}{2}$, the electricity generation enterprise sells electricity to the electricity retailer enterprise at a cost that promotes the portfolio contract to be implemented $\left(\gamma^{s^{*}}, \theta^{s^{*}}\right)$.

Proposition 6.1 shows that when observing equations (6.9) and (6.10), we can see that the proportion of revenue sharing $\theta$ would affect the profit distribution of the electricity generation enterprise and electricity sales electricity retailer enterprise in the coordination contract. Specifically, the profit of electricity retailer enterprise would increase $\left(\partial \pi_{r}^{s^{*}} / \partial \theta>0\right)$. Meanwhile, the profit of electricity generation enterprises would decrease $\left(\partial \pi_{m}^{s^{*}} / \partial \theta<0\right)$. Therefore, the supply chain's system profit could be distributed by setting the revenue sharing proportion. According to equation (6.11), the system profit in the coordinated decision is equal to the centralized decision, indicating that the contract is effective. Further, the electricity generation enterprise sells electricity to electricity retailer enterprises at a cost price. The profits of supply chain enterprises in the coordinated system are greater than those in the decentralized system, which shows that this contract is feasible.

\section{NumericAl ANALYSiS}

The following will be analyzed via a numerical analysis method to describe the influence of exogenous parameters on the optimal profit of supply chain enterprises. Specifically, we will analyze (1) the impact of the electricity service quality sensitivity coefficient on the profits, (2) the impact of the electricity service quality cost coefficient on the profit, and (3) the impact of electricity production cost on the profit. According to the conditions of the theoretical solution, it is assumed that the parameter is as follows: $a_{d}=25, a_{n}=10, b=0.5, \theta=0.3$.

\subsection{Influence of electricity service quality sensitivity coefficient}

The influence of the electricity service quality sensitivity coefficient on the optimal profit will be analyzed in detail. First, the fixed exogenous parameters $h=5, c=1$ will be in the range of the electricity service quality sensitivity coefficient $d \in[0,1]$. Second, comparative static results describe the electricity service quality sensitivity coefficient. The following conclusions are drawn from Figure 1: 


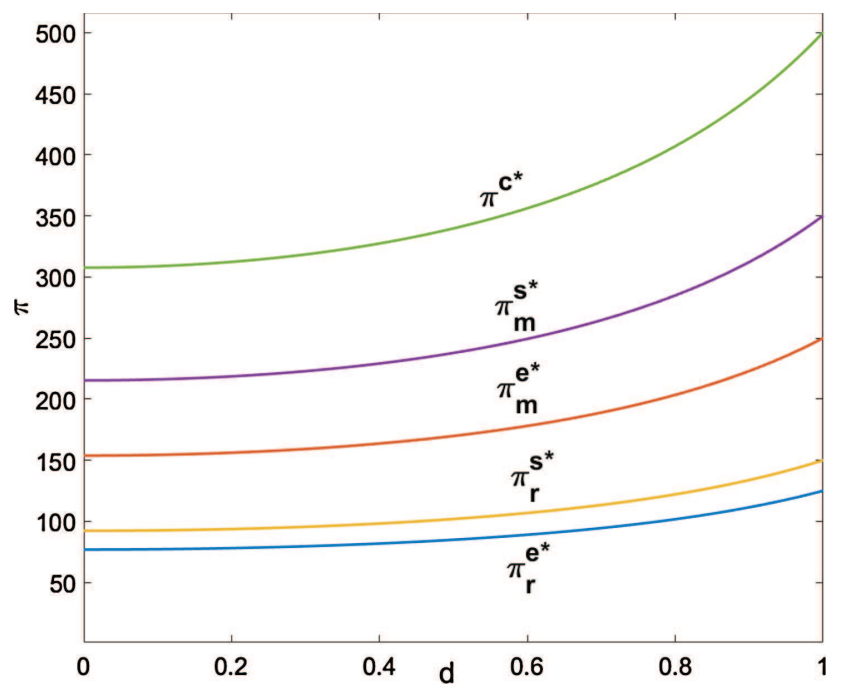

FIGURE 1. Impact of the electricity service quality sensitivity coefficient on the profit.

(1) Profits increase with the electricity service quality sensitivity coefficient. The increase of consumers' sensitivity to electricity service quality means that consumers are willing to buy more electricity with this quality service, increasing the profits of supply chain enterprises. It suggests that supply chain enterprises should improve the electricity quality and increase publicity on electricity quality so that consumers can gain more information about the electricity quality. Reducing the information asymmetry between consumers and supply chain enterprises will improve social welfare.

(2) The total profit of the centralized system $\left(\pi^{c^{*}}\right)$ is greater than that of the decentralized system $\left(\pi_{m}^{e^{*}}+\pi_{r}^{e^{*}}\right)$. This shows that the coordination contract is effective. The centralized system eliminates the internal transaction cost and improves the profits of power supply chain enterprises. It suggests that internal transaction costs should be consumed as much as possible from the perspective of the system profit. Further, the cooperation between the electricity generation enterprise and the electricity retailer enterprise should be strengthened.

(3) Whether in the decentralized or coordinated system, the profit of electricity generation enterprises $\left(\pi_{m}^{s^{*}}, \pi_{m}^{e^{*}}\right)$ is greater than the profit of the electricity retailer enterprise $\left(\pi_{r}^{s^{*}}, \pi_{r}^{e^{*}}\right)$. The electricity generation enterprises have the first-mover advantage. Therefore, they can prioritize making decisions conducive to their own profit. Meanwhile, the electricity retailer enterprise is a follower of the electricity supply chain. It can only optimize its profits according to the decision by the electricity generation enterprise. It suggests that electricity generation enterprises as leaders can gain more benefits, whereas electricity retailer enterprises as followers receive fewer benefits. From the perspective of profit, enterprises should gain leadership.

(4) The profits of the coordinated supply chain enterprises are always greater than those of the decentralized system. This shows that the coordination contract is feasible. The most important aspect in designing a contract is to improve the profits of supply chain enterprises. The effectiveness of the contract can only be proved if the profits of supply chain enterprises are improved. Meanwhile, it also shows that the contract can reduce the internal cost among supply chain enterprises.

\subsection{Influence of electricity service quality cost coefficient}

The influence of the electricity service quality cost coefficient on the optimal profit will be analyzed in detail. First, the fixed exogenous parameters $d=0.1, c=1$ will be in the range of the electricity service quality cost 


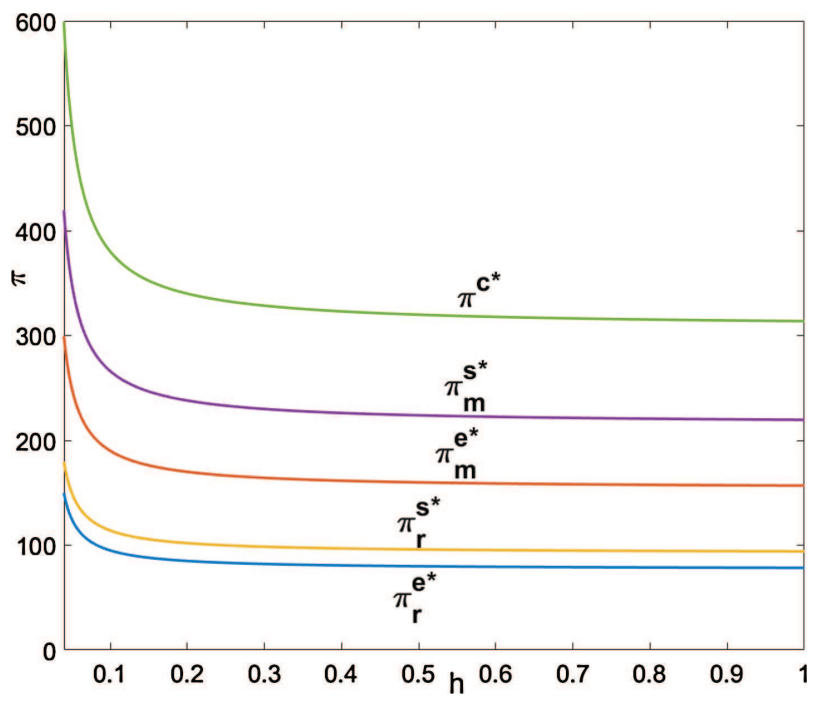

FIGURE 2. Impact of the electricity service quality cost coefficient on the profit.

coefficient $h \in[0,1]$. Second, comparative static results describe the electricity service quality cost coefficient. The following conclusions are drawn from Figure 2:

(1) The profits decrease with the electricity service quality cost coefficient. The increase of the electricity service quality cost coefficient means that the electricity retailer enterprise investing in electricity service quality would increase, weakening the motivation of the electricity retailer enterprise to invest in electricity service quality and reduce the profits of the supply chain enterprises. Furthermore, reducing the electricity service quality cost coefficient would help improve the profit of electricity retailer enterprise profit, reduce the pressure of production enterprises, and release more economic vitality. For example, in 2021, Baotou City, with an average electricity connection time limit of 2.8 working days, saved 68.94 million yuan of customer electricity consumption cost, $99.92 \%$ of customer satisfaction rate ${ }^{3}$.

(2) The profit of the centralized system is higher than that of the decentralized system, indicating that the electricity supply chain needs coordination. After the coordination system, the enterprise's profit is higher than in the decentralized system, verifying the effectiveness and feasibility of the coordination contract. The profits of the electricity generation enterprise are higher than that of the electricity retailer enterprise, showing that enterprises have the first-mover advantage in the supply chain. It suggests that designing appropriate contracts can stimulate the vitality among supply chain enterprises and improve profits. Therefore, the government should encourage supply chain enterprises to strengthen cooperation via contracts.

\subsection{Influence of electricity production cost}

The influence of the electricity production cost on the optimal profit will be analyzed in this section. First, the fixed exogenous parameters $h=5, d=0.1$ will be in the range of the electricity production cost coefficient $c \in[0,1]$. Second, the comparative static results describe the electricity production cost coefficient. The following conclusions are drawn from Figure 3:

(1) The profits decrease with the electricity production cost. The increase in the electricity production cost means that the electricity generation enterprise's electricity production cost would increase. This would weaken the motivation of the electricity generation enterprise to produce electricity and reduce the profits

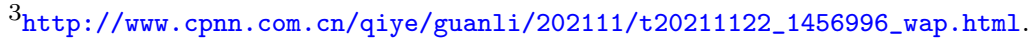




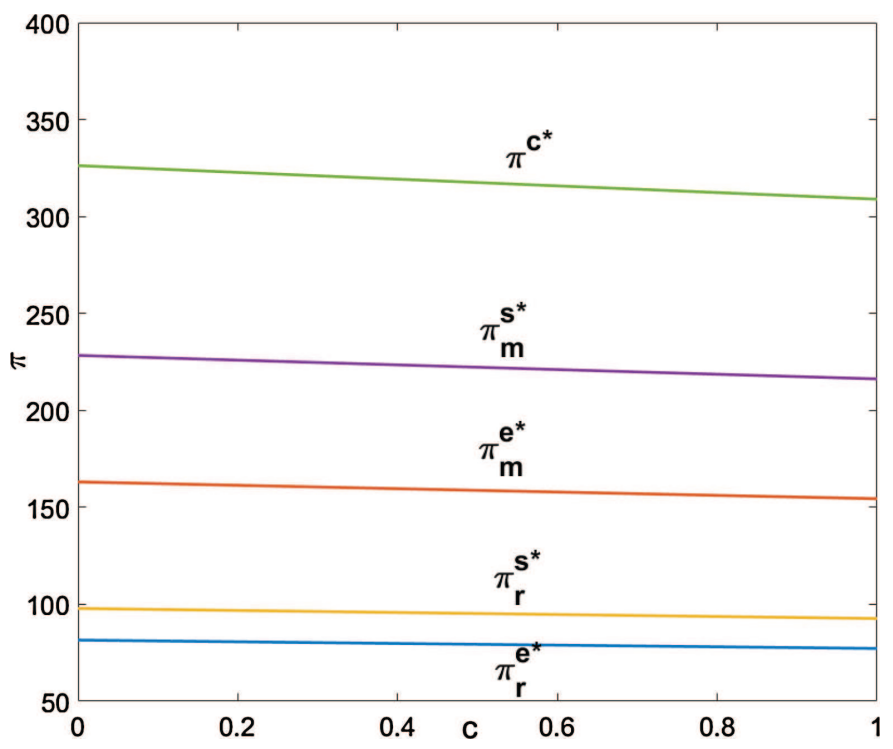

FiguRE 3. Impact of the electricity production cost on the profit.

of supply chain enterprises. Moreover, reducing electricity production costs improves the profits of supply chain enterprises and reduces the pressure on consumers. For example, Changsha achieved zero certificate electricity handling, and the average electricity receiving time of high-voltage customers and low-voltage small and micro enterprises decreased by $22.36 \%$ and $45.16 \%$, respectively, year-on-year, saving customers' electricity handling costs of about 1.41 billion yuan ${ }^{4}$. Therefore, the government should encourage supply chain enterprises to invest in electricity production to reduce production costs.

(2) It also shows that the centralized system's decision-making profit is higher than that of the decentralized system, indicating that the electricity supply chain needs coordination. After adopting the cost-sharing and revenue-sharing contract, the enterprise's profit after coordination is higher than that in the decentralized system, further verifying the effectiveness and feasibility of the coordination contract. Moreover, it shows that the contract can increase the profits of the electricity generation enterprise more, whereas the profits of the electricity retailer enterprise increase less. Thus, the electricity generation enterprise should increase the profits of the $p$ electricity retailer enterprise more so that the contract can be carried out better.

\section{CONCLusion}

Although many papers have studied the problems of service quality decision-making and contract coordination of supply chain enterprises, there is a lack of research considering electricity peak-valley pricing in the electricity market. Therefore, this paper builds an electricity supply chain composed of the electricity generation enterprise and the electricity retailer enterprise. The electricity generation enterprise first decides the wholesale electricity price. The electricity retailer enterprise then decides the electricity service quality and peak-valley pricing. Based on this, this paper considers three game models: decentralization, centralization, and coordination. This paper compares the equilibrium electricity service quality, peak-valley price, demand, and supply chain enterprise's profit among different models. It further analyzes the influence of the electricity service quality sensitivity coefficient, electricity service quality cost coefficient, and electricity production cost on the above equilibrium solution.

\footnotetext{
$4_{\text {https }}$ // baijiahao. baidu. com/s?id=1690560199966420004\&wfr=spider\&f or=pc.
} 
The main conclusions are obtained as follows. First, compared with the decentralized system, the centralized system provides a lower peak-valley price, higher electricity service quality, electricity demand, and supply chain's profit. Second, the profits of the electricity generation enterprise are higher than those under the electricity retailer enterprise. Third, with the service quality sensitivity coefficient, the electricity service quality, electricity price, and electricity demand would increase, increasing the profit. Fourth, with the electricity service quality cost coefficient, the electricity service quality, electricity price, and electricity demand would decrease, reducing the profit. Fifth, the revenue sharing and electricity service quality investment cost-sharing contract could achieve the coordination of the supply chain.

Although this paper studies the background of the electricity supply chain and investigates the electricity service quality, peak-valley electricity pricing, and contract coordination, future research can be expanded from the following aspects. First, this paper only studies the game between single subjects, which could be further extended to the game between multiple subjects. Second, this paper only studies the investment in electricity service quality. The investment of energy storage equipment in the electricity generation enterprise is also worth studying. Finally, the peak-valley pricing considered in this paper could be extended to the field of dynamic pricing [15].

\section{Appendix A.}

Proof of Proposition 4.2. Using Proposition 4.1, we have the following:

$$
\begin{aligned}
q_{d}^{e^{*}}-q_{n}^{e^{*}}= & \frac{1}{4}\left(a_{d}-a_{n}\right)>0 \\
\pi_{r}^{e^{*}}-\pi_{m}^{e^{*}}= & -\frac{\left\{\begin{array}{c}
4 h c^{2}(1+b)(1-b)^{2}+\left(2 h-d^{2}\right)\left(a_{d}^{2}+a_{n}^{2}\right) \\
-4 c h a_{n}\left(1-b^{2}\right) \\
+2 a_{d}\left[a_{n}\left(d^{2}+2 b h\right)-2 c h\left(1-b^{2}\right)\right]
\end{array}\right\}}{32(1+b)\left[(1-b) h-d^{2}\right]}<0 .
\end{aligned}
$$

Proof of Proposition 4.3. Using Proposition 4.1, we have the following:

$$
\begin{aligned}
\frac{\partial p_{d}^{e^{*}}}{\partial d} & =\frac{d h\left[a_{d}+a_{n}-2 c(1-b)\right]}{4\left[d^{2}-(1-b) h\right]^{2}}>0 \\
\frac{\partial p_{n}^{e^{*}}}{\partial d} & =\frac{d h\left[a_{d}+a_{n}-2 c(1-b)\right]}{4\left[d^{2}-(1-b) h\right]^{2}}>0 \\
\frac{\partial k^{e^{*}}}{\partial d} & =\frac{\left(d^{2}+h-b h\right)\left[a_{d}+a_{n}-2 c(1-b)\right]}{4\left[d^{2}-(1-b) h\right]^{2}}>0 \\
\frac{\partial q_{d}^{e^{*}}}{\partial d} & =\frac{d h(1-b)\left[a_{d}+a_{n}-2 c(1-b)\right]}{4\left[d^{2}-(1-b) h\right]^{2}}>0 \\
\frac{\partial q_{n}^{e^{*}}}{\partial d} & =\frac{d h(1-b)\left[a_{d}+a_{n}-2 c(1-b)\right]}{4\left[d^{2}-(1-b) h\right]^{2}}>0 .
\end{aligned}
$$

Proof of Proposition 4.4. Using Proposition 4.1, we have the following:

$$
\frac{\partial p_{d}^{e^{*}}}{\partial h}=-\frac{d^{2}\left[a_{d}+a_{n}-2 c(1-b)\right]}{8\left[d^{2}-(1-b) h\right]^{2}}<0
$$




$$
\begin{aligned}
\frac{\partial p_{n}^{e^{*}}}{\partial h} & =-\frac{d^{2}\left[a_{d}+a_{n}-2 c(1-b)\right]}{8\left[d^{2}-(1-b) h\right]^{2}}<0 \\
\frac{\partial k^{e^{*}}}{\partial h} & =-\frac{d(1-b)\left[a_{d}+a_{n}-2 c(1-b)\right]}{4\left[d^{2}-(1-b) h\right]^{2}}<0 \\
\frac{\partial q_{d}^{e^{*}}}{\partial h} & =-\frac{(1-b) f^{2}\left[a_{d}+a_{n}-2 c(1-b)\right]}{8\left[d^{2}-(1-b) h\right]^{2}}<0 \\
\frac{\partial q_{n}^{e^{*}}}{\partial h} & =-\frac{(1-b) d^{2}\left[a_{d}+a_{n}-2 c(1-b)\right]}{8\left[d^{2}-(1-b) h\right]^{2}}<0 .
\end{aligned}
$$

Proof of Proposition 4.5. Using Proposition 4.1, we have the following:

$$
\begin{aligned}
\frac{\partial p_{d}^{e^{*}}}{\partial c} & =\frac{(1-b) h-2 d^{2}}{4 d^{2}}>0 \\
\frac{\partial p_{n}^{e^{*}}}{\partial c} & =\frac{(1-b) h-2 d^{2}}{4 d^{2}}>0 \\
\frac{\partial k^{e^{*}}}{\partial c} & =-\frac{(1-b) d}{2\left[(1-b) h-d^{2}\right]}<0 \\
\frac{\partial q_{d}^{e^{*}}}{\partial c} & =-\frac{h(1-b)^{2}}{4\left[(1-b) h-d^{2}\right]}<0 \\
\frac{\partial q_{n}^{e^{*}}}{\partial c} & =-\frac{h(1-b)^{2}}{4\left[(1-b) h-d^{2}\right]}<0 .
\end{aligned}
$$

Proof of Proposition 5.2. Using Propositions 4.1 and 5.1, we have the following:

$$
\begin{aligned}
& k^{c^{*}}-k^{e^{*}}=\frac{d\left[a_{d}+a_{n}-2 c(1-b)\right]}{4\left[(1-b) h-d^{2}\right]}>0
\end{aligned}
$$

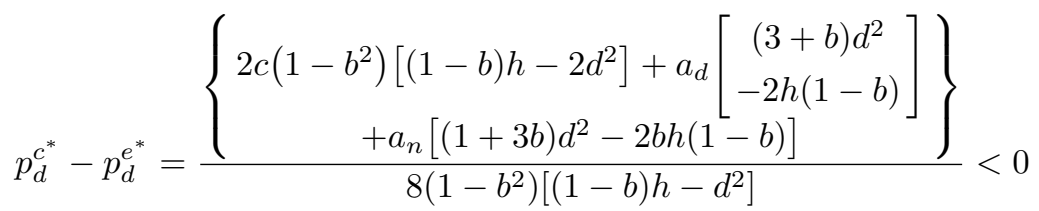

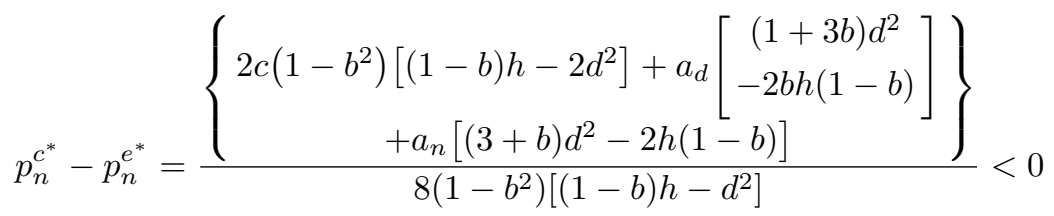

$$
\begin{aligned}
& q_{d}^{c^{*}}-q_{d}^{e^{*}}=\frac{a_{d}\left[2 h(1-b)-d^{2}\right]+a_{n} d^{2}-2 c h(1-b)^{2}}{8\left[(1-b) h-d^{2}\right]}>0 \\
& q_{n}^{c^{*}}-q_{n}^{e^{*}}=\frac{a_{d} d^{2}+a_{n}\left[2 h(1-b)-d^{2}\right]-2 c h(1-b)^{2}}{8\left[(1-b) h-d^{2}\right]}>0
\end{aligned}
$$




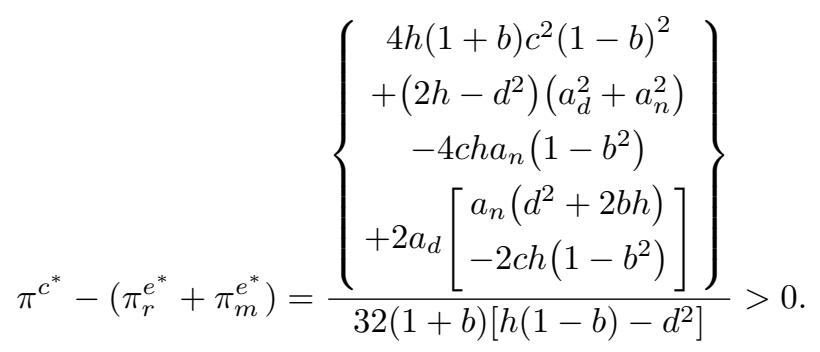

Acknowledgements. The authors gratefully acknowledge financial support from the Financed by the Philosophy and Social Science Research Fund of Chengdu University of Technology (YJ2021-QN005) and the National Natural Science Foundation of China (Grant No. 71531003).

\section{REFERENCES}

[1] Z. Alzaydi, The effect of intangible service quality on retailing during the COVID-19 pandemic in Saudi Arabia. Manage. Sci. Lett. 11 (2021) 2279-2290.

[2] S. Borenstein, Effective and equitable adoption of opt-in residential dynamic electricity pricing. Rev. Ind. Org. 42 (2013) $127-160$.

[3] Z. Cao and J. Min, Selection and impact of decision mode of encroachment and retail service in a dual-channel supply chain. J. Ind. Manage. Optim. 18 (2022) 541.

[4] H. Chao, Efficient pricing and investment in electricity markets with intermittent resources. Energy Policy 39 (2011) $3945-3953$.

[5] J.X. Chen, L. Liang, D.Q. Yao and S.N. Sun, Price and quality decisions in dual-channel supply chains. Eur. J. Oper. Res. 259 (2017) 935-948.

[6] W. Chen, Y. Ma and C. Bai, The impact of carbon emission quota allocation regulations on the investment of lowcarbon technology in electric power industry under peak-valley price policy. IEEE Trans. Eng. Manage. (2021) DOI: 10.1109/TEM.2021.3121002.

[7] B. Dan, G. Xu and C. Liu, Pricing policies in a dual-channel supply chain with retail services. Int. J. Prod. Econ. 139 (2012) $312-320$.

[8] B. Dan, S. Zhang and M. Zhou, Strategies for warranty service in a dual-channel supply chain with value-added service competition. Int. J. Prod. Res. 56 (2018) 5677-5699.

[9] N.R. Darghouth, G. Barbose and R. Wiser, The impact of rate design and net metering on the bill savings from distributed PV for residential customers in California. Energy Policy 39 (2011) 5243-5253.

[10] N. Ertekin, M.E. Ketzenberg and G.R. Heim, Assessing impacts of store and salesperson dimensions of retail service quality on consumer returns. Prod. Oper. Manage. 29 (2020) 1232-1255.

[11] D. Fang, C. Zhao and Q. Yu, Government regulation of renewable energy generation and transmission in China's electricity market. Renewable Sustainable Energy Rev. 93 (2018) 775-793.

[12] P. Faria and Z. Vale, Demand response in electrical energy supply: an optimal real time pricing approach. Energy 36 (2011) 5374-5384.

[13] A. Faruqui and S. Sergici, Household response to dynamic pricing of electricity: a survey of 15 experiments. J. Regul. Econ. 38 (2010) 193-225.

[14] J. Han, N. Liu, Y. Huang and Z. Zhou, Collaborative optimization of distribution network and 5G mobile network with renewable energy sources in smart grid. Int. J. Electr. Power Energy Syst. 130 (2021) 107027.

[15] F. Huang, P. Guo and Y. Wang, Cyclic pricing when customers queue with rating information. Prod. Oper. Manage. 28 (2019) 2471-2485.

[16] A.G. Kök, K. Shang and Ş. Yücel, Impact of electricity pricing policies on renewable energy investments and carbon emissions. Manage. Sci. 64 (2016) 131-148.

[17] I. Koutsopoulos and L. Tassiulas, Challenges in demand load control for the smart grid. IEEE Network 25 (2011) 16-21.

[18] Q. Li and B. Li, Dual-channel supply chain equilibrium problems regarding retail services and fairness concerns. Appl. Math. Modell. 40 (2016) 7349-7367.

[19] W.H. Liu and D. Xie, Quality decision of the logistics service supply chain with service quality guarantee. Int. J. Prod. Res. 51 (2013) 1618-1634.

[20] M. Miao, S. Lou, Y. Zhang and X. Chen, Research on the optimized operation of hybrid wind and battery energy storage system based on peak-valley electricity price. Energies 14 (2021) 3707.

[21] A. Mills, R. Wiser, G. Barbose and W. Golove, The impact of retail rate structures on the economics of commercial photovoltaic systems in California. Energy Policy 36 (2008) 3266-3277. 
[22] B. Pal, A. Mandal and S.S. Sana, Two-phase deteriorated supply chain model with variable demand and imperfect production process under two-stage credit financing. RAIRO-Oper. Res. 55 (2021) 457-480.

[23] M. Sarkar and B.D. Chung, Flexible work-in-process production system in supply chain management under quality improvement. Int. J. Prod. Res. 58 (2020) 3821-3838.

[24] B. Sarkar, M. Sarkar, B. Ganguly and L.E. Cárdenas-Barrón, Combined effects of carbon emission and production quality improvement for fixed lifetime products in a sustainable supply chain management. Int. J. Prod. Econ. 231 (2021) 107867.

[25] A.A. Tsay and A. Narendra, Channel dynamics under price and service competition. Manuf. Serv. Oper. Manage. 2 (2000) $372-391$.

[26] D. Yang and T. Xiao, Coordination of a supply chain with loss-averse consumers in service quality. Int. J. Prod. Res. 55 (2017) 3411-3430.

[27] X. Yao, Y. Fan, F. Zhao and S.C. Ma, Economic and climate benefits of vehicle-to-grid for low-carbon transitions of power systems: a case study of China's 2030 renewable energy target. J. Cleaner Prod. 330 (2022) 129833.

[28] Y.W. Zhou, J. Guo and W. Zhou, Pricing/service strategies for a dual-channel supply chain with free riding and service-cost sharing. Int. J. Prod. Econ. 196 (2018) 198-210.

\section{Subscribe to Open (S2O) A fair and sustainable open access model}

This journal is currently published in open access under a Subscribe-to-Open model (S2O). S2O is a transformative model that aims to move subscription journals to open access. Open access is the free, immediate, online availability of research articles combined with the rights to use these articles fully in the digital environment. We are thankful to our subscribers and sponsors for making it possible to publish this journal in open access, free of charge for authors.

\section{Please help to maintain this journal in open access!}

Check that your library subscribes to the journal, or make a personal donation to the $\mathrm{S} 2 \mathrm{O}$ programme, by contacting subscribers@edpsciences.org

More information, including a list of sponsors and a financial transparency report, available at: https://www. edpsciences.org/en/maths-s2o-programme 